\title{
PSYCHE.
}

\section{A NEW SPECIES OF TIPULA WITH VESTIGIAL WINGS.}

\author{
BY R. W. DOANE, STANFORD UNIVERSITY, CAL.
}

Tipula vestigipennis n. sp. Brownish yellow; head and rostrum yellowish, grayish above, sometimes with a brownish stripe: palpi yellowish at the base, brownish toward the tip; first, second and third segments of the antennæ yellow, the latter darker toward the tip, the remaining segments brownish, growing darker toward the tip of the antennæ, finely pubescent, with the black bases slightly swollen and furnished with a whorl of four or five rather stiff hairs; collar yellowish with median and lateral brownish spots; dorsum of thorax light yellow, dorsal stripes yellow, often indistinct, median stripe divided by a rather broad yellow line; pleura and coxæ hoary; scutellum yellow, lighter laterally, with a narrow median brown line; metanotum light yellow; halteres yellow, knobs black; femora and tibia yellowish, much darker toward the tip; tarsi brownish to blackish; abdomen with broad dorsal, lateral and ventral brown stripes; seventh and eighth segments often almost wholly blackish or brownish; posterior margin of the eighth sternite of the male gently curved, with a broad shallow median incision which is usually filled with the light colored membrane from which arise two tufts of very light yellow hairs, these tufts cross each other close to the base at an angle of about forty-five degrees; to the lateral margins of this sternite are attached rather broad sub-triangular chitinized plates which stand at right angles to the sternite; posterior margin of the ninth tergite with a broad rather shallow circular incision from the middle of which arise two short triangular processes; ovipositor long, rather stout, upper valves straight, acute, lower valves reaching almost to the tip of the upper valves, tips rounded; wings small, more or less distorted, sometimes but little longer than the halteres, sometimes twice as long; veins more or less distinct but crowded together and deformed as shown in the figures. Length, male $15 \mathrm{~mm}$., wing 5 to $9 \mathrm{~mm}$.; Female $22 \mathrm{~mm}$., wing $5 \mathrm{~mm}$. to $6 \mathrm{~mm}$. Hab. San Francisco, Cal., four males, three females. Collected by Mr. F. X. Williams, Stanford University, one female.

Osten Sacken in his "Western Diptera" (p. 209) after referring to Tipula pracisa Lw. as a common California species says, "I have two males from Brooklyn, 
Alameda Co., Cal., with abortive wings which are hardly twice as long as the halteres; in all the other characters, as well as in the structure of the hypopygium, they agree with the males of $T$. prcccisa. I suppose this is a case of dimorphism." He then mentions this species as having been taken at the same time and place as the apterous Bitticus which is rather common at times.

For a long time we have had in our collections here at Stanford a poorly preserved sub-apterous female Tipula which I have been unable to identify. Indeed I thought it might be one of the common species that had failed to expand its wings after issuing from the pupa. Last winter however Mr. Williams found these sub-apterous forms very common in and about San Francisco and the three pairs that he brought in show that they cannot be placed with $T$. proceisa, which they, at first sight, closely
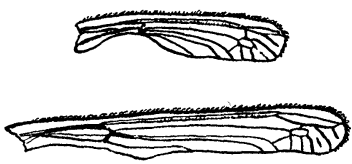

Wings of Tipula vestigipennis resemble except for the short wings. They differ from procisa in several respects, the most important of which are in the structure of the hypopygia and the ovipositors. In pracisa, which is one of our most common California forms, the posterior margin of the eighth sternite of the male has a very deep rounded incision which is bordered, broadly toward the apex, narrowly on the sides, by a lighter colored membrane from the middle of which arise two parallel tufts of long reddish hairs. In vestigipennis this sternite is only gently excised medianly, the whitish membrane almost or quite filling the incision. The two tufts of whitish hairs which arise from this membrane instead of extending parallel cross each other close to the base at an angle of about forty-five degrees. The posterior margin of the ninth tergite of the male of prcecisa has a very deep broad V-shaped incision which almost or quite divides the tergite. In vestigipennis the posterior margin of this tergite is gently rounded with a median pair of brownish triangular processes. There are other differences in the hypopygia but these are the most striking and easily detected. The most noticeable difference in the ovipositors of the two species is in the shape of the tip of the upper lamella. In procisa they are obliquely truncated and slightly excised. In vestigipennis they are drawn out to a very sharp point.

So we have here not a case of dimorphism as Osten-Sacken suspected, but another species of this family Tipulidæ, which is so abundantly represented in California, in which the wings are apparently becoming vestigial. The fact that there is so great a variation in the degree of development in the few specimens before me would indicate, it seems, that this tendency or condition is only a recently acquired one for although they can no longer serve as organs of flight they have by no means reached the stage of degeneration that is represented by the females of Tipula simplex Doane. (Ento. News, Vol. 18, No. 1.) 
So far this species has been recorded as most abundant in the wind-swept hills southwest of San Francisco where Mr. Williams says they occurred by the hundreds, usually on the sides of the hills away from the ocean or in the lower places between the hills. This would at first suggest that the winds might be a factor in this change that is being brought about but the same species is also found further inland where strong winds very rarely occur. As pointed out in the article on T. simplex we can hardly see how natural selection can be the cause of such changes as this. Heterogenesis would more easily explain such cases.

We propose, if possible, to study large series of these for a few years to see if any appreciable change is actually taking place at the present time. 

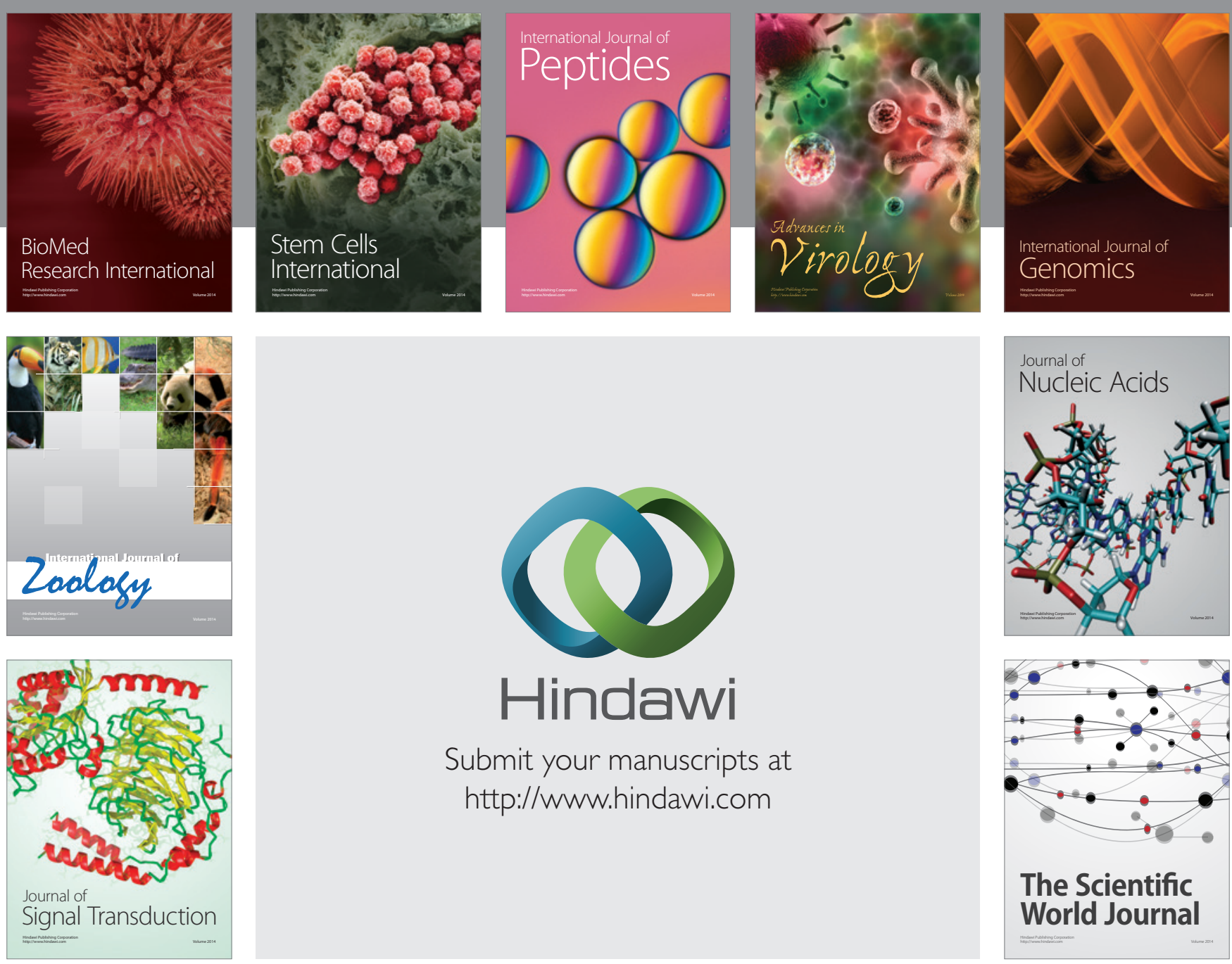

Submit your manuscripts at

http://www.hindawi.com
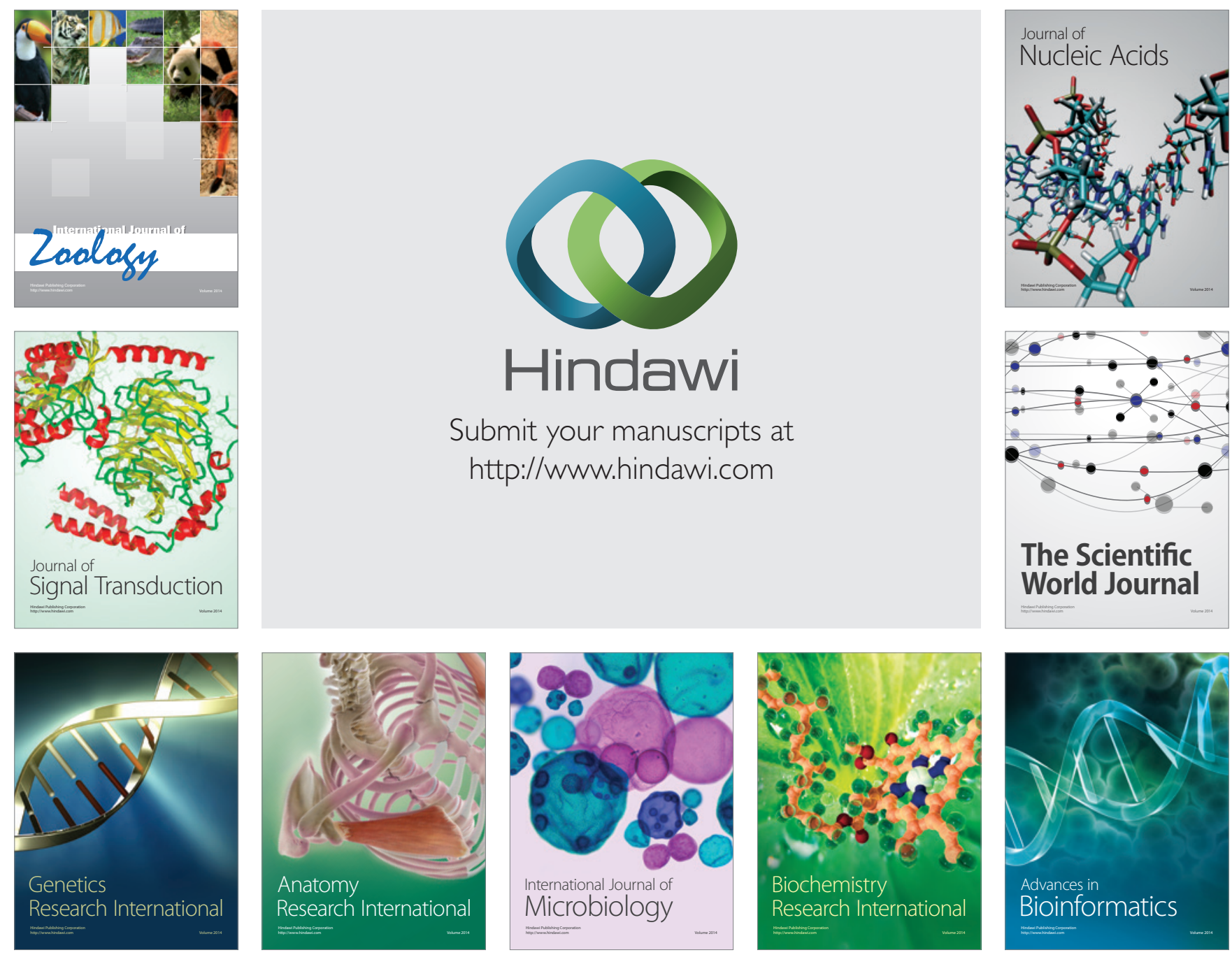

The Scientific World Journal
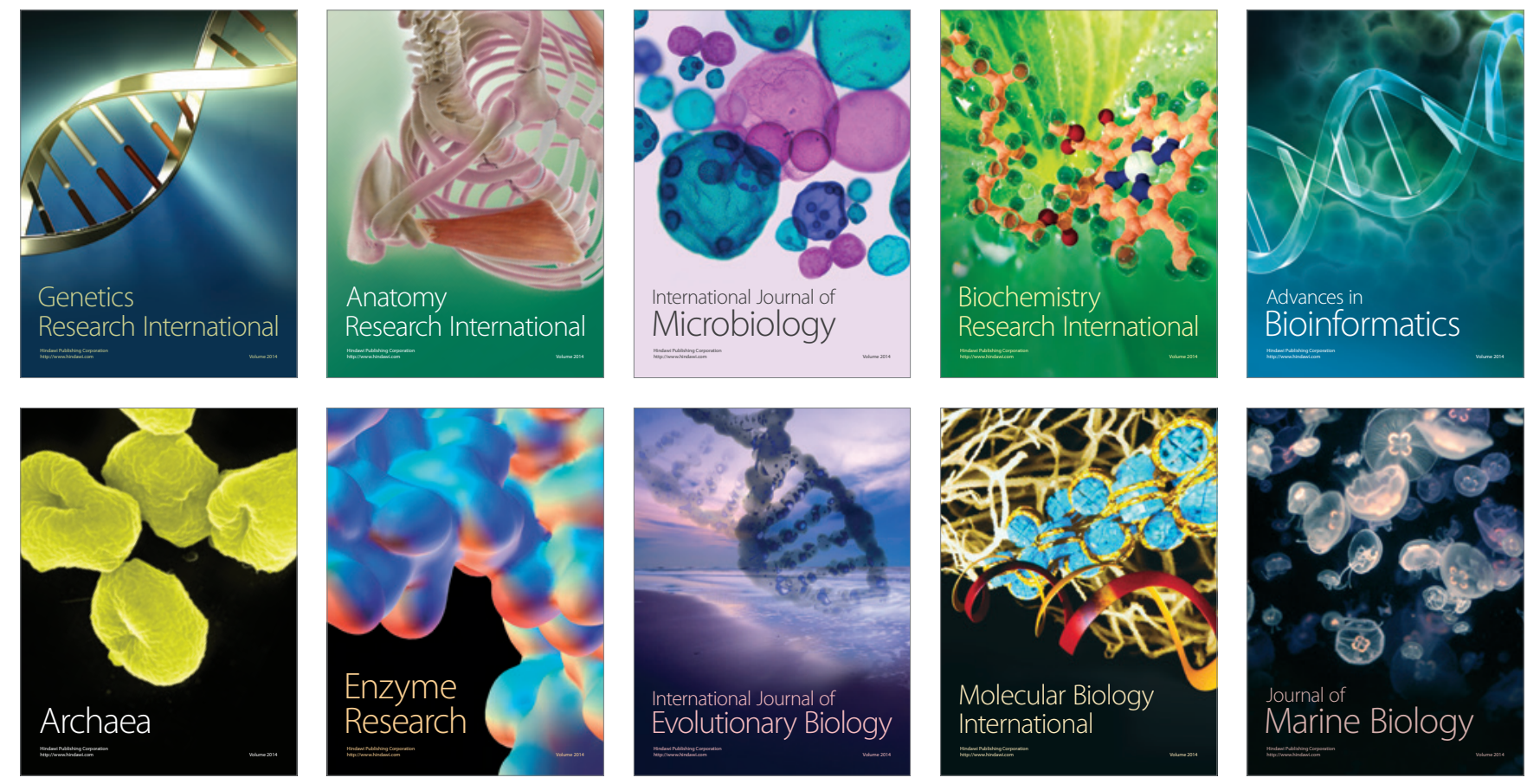